\title{
Development of an RFID-based Surgery Management System: Lesson Learnt from a Hong Kong Public Hospital
}

\author{
S.L. Ting, PhD* and Albert H.C. Tsang, PhD \\ Department of Industrial and Systems Engineering, The Hong Kong Polytechnic \\ University, Hung Hom, Kowloon, Hong Kong
}

Submitted December 2011. Accepted for publication February 2012.

\begin{abstract}
Medical errors happen during surgery such as leaving medical instruments in patient's body after surgery. In recent years, numerous cases have shown successful applications of Radio Frequency Identification (RFID) technology in hospitals. This paper aims to investigate the potential applications of RFID in surgery management in a Hong Kong public hospital where the nurse to patient ratio is much lower than other countries. An RFID-based Surgery Management System is proposed to tackle the problems identified in the current situation. Apart from helping to reduce medical errors and enhance patient safety, it is expected that this system will also reduce the workload of care givers so that they can put more emphasis on providing high quality services to patients.
\end{abstract}

Keywords: radio frequency identification (RFID), surgery management system, hospital, patient safety

\section{INTRODUCTION}

It has become a great concern in today's healthcare sector as World Health Organization [1] reported that one in ten people will be harmed while receiving health services. Medical errors made in hospital often produce adverse effects on patients' health and in some extreme cases, they may result in loss of human lives.

In recent years, Hong Kong's healthcare sector faces more challenges than those in other countries. Although numerous policies, such as "Three Checks Eight Matches" in daily hospital operations, patient safety round and two-dimension (2D) barcode [2], have been adopted by hospitals to reduce medical errors, evidences have shown that

*Corresponding Author: S.L. Ting, Department of Industrial and Systems Engineering, The Hong Kong Polytechnic University, Hung Hom, Kowloon, Hong Kong. Phone: (852) 2766-6613. Fax: (852) 2774-9308. E-mail: jacky.ting@connect.polyu.hk. Other author: mfalbert@inet.polyu.edu.hk. 
those practices are not very effective in enhancing patient safety. In 2009 and 2010, 33 cases of sentinel events and 81 cases of serious untoward events were reported [3]. The figure of reported cases of "retained instruments or other material after surgery/interventional procedure" attributes to $36.4 \%$ of all reported cases which ranked the top among others, whereas the third top ranking medical error is "surgery/interventional procedure involving the wrong patient or body part" which contributed to $15.2 \%$ of all reported cases. These statistics indicate that medical errors arising from surgery are amongst the most frequently occurring categories of medical incidents. Therefore, more attention should be paid to address such problems immediately.

Heavy staff workload is one of the reasons why the number of surgery-related medical errors is so high. According to a survey conducted by Association of Hong Kong Nursing Staff [4], the nurse to patient ratio is one to $10-12$ in public hospitals. This ratio is much higher than those in other countries. This creates huge pressure on nurses every day, and increases the chance of making mistakes in medical processes. In order to improve the situation, public hospitals have employed barcode technology to identify patients so as to ensure that the right services are provided to the right patients. However, bar code technology is not effective enough to enhance patient safety [5]. As discussed in the literature [6-9], four critical areas are identified in the current surgery operations in public hospitals, including (i) inefficient workflow of surgery, (ii) lack of automatic alert after a medical equipment is lost, (iii) inability to track patients' movement, and (iv) inaccurate identification of patients. With a view to improving the current situation in surgery management, the healthcare sector is looking for a new technology to improve patient safety, streamline processes such as patient identification and tracking, and reduce staff workload [9]. Radio Frequency Identification (RFID) has high potential for such applications [10].

RFID technology provides quality data and enhances enterprise collaboration by automatically acquiring product information. It has proved its benefits in various applications such as supply chain management optimization, business automation, intelligent asset management, and anti-counterfeiting [11]. It is a data acquisition and storage method that provides accurate, real-time data without human intervention, making it a powerful technology that has gained popularity in research work and various industries [12].

There are five main components in an RFID system [13]:

- Tag (attached to an object, for unique identification)

- Antenna (tag detector, creates magnetic field)

- Reader (receiver of tag information, manipulator)

- Communication infrastructure (enable reader/RFID to work through IT infrastructure)

- Middleware/Application software (user database/application/interface) 
Signals are emitted by readers through antennas to the tag. The tag responds by sending its unique identification number back to the readers where the data are transmitted to the middleware for filtering. Useful data are then stored in the database system. Finally, the data are forwarded to other enterprise application systems for further processing.

In this paper, we focus on the application of RFID in surgery management. The benefits of applying an RFID-based Surgery Management System include enhanced operational efficiency and patient safety in which the latter relates to assuring that the specified course of medical treatment will proceed correctly [14]. The significance and benefits of adopting an RFID-based Surgery Management System will be illustrated in this paper via a case study in a Hong Kong public hospital. Recognizing the importance of improving operational efficiency and enhancing patient safety in surgery processes of hospitals, this paper aims to investigate how RFID technology can help to address these two issues. The methodology of this study follows the conventional procedure for systems engineering development [15]. The current processes are first reviewed to identify error prone areas, and the feasibility of using RFID in hospitals is studied via a case study. The architectural framework of the RFID-based Surgery Management System is then proposed and designed to address the identified problems. More specifically, the potential areas for improvement are measured in terms of several common key performance indicators (reduction in medical errors and workloads, cost saving, improvement of public confidence) [16] and the critical success factors for adoption of RFID in surgery processes are discussed.

Even though some studies [e.g., 9, 13] have identified critical factors for successful RFID adoption, they mainly focused on the deployment pre-requisites, rather than issues at the implementation and maintenance stages (and not in the surgery procedures perspective). On the other hand, this study investigates the RFID implementation and maintenance in an actual healthcare environment and focuses on real-life surgery scenarios/procedures.

The paper is divided into six sections. Section 1 is the introduction. Section 2 presents a review on the literature relating to patient safety and RFID systems. In Section 3, the current workflows of surgery process are investigated and hence the areas for improvement are identified. In Section 4, an RFID-based system is presented to address the challenges faced in the surgery management situation. Section 5 discusses the implications of the proposed system. Finally, in Section 6, the research findings of this study are summarized and conclusions are drawn.

\section{LITERATURE REVIEW}

\subsection{Patient Safety}

Any mistake during the process of treatment would threaten patient safety. A recent Institute of Medicine study reported that there were more than 400,000 preventable injuries each year in hospitals alone, and that altogether medication errors harmed at 
least 1.5 million people [17]. These medical incidents are preventable if proper technology and practices are employed. Given the seriousness of patient safety failures, six goals related to enhancing patient safety in hospitals were proposed by the Joint Commission on Accreditation of Healthcare Organizations [18]. They are (i) accuracy of patient identification, (ii) effective communication among medical care providers, (iii) ensuring that the medicines used are safe, (iv) avoiding infections by adhering to guidelines, (v) confirming the medicines patient takes, and (vi) classifying patient safety risks. Liao et al. [19] share the same view that patient safety is the most important issue in healthcare industry. Building up a patient-safety environment can provide higher quality services and minimize medical errors.

However, despite the various efforts made to improve safety performance, the number of preventable patient safety incidents and medical errors (such as administering incorrect type or dosage of drugs, performing transfusion by using the wrong type of blood, and mislabeling blood samples) continues to rise [20]. This reveals that numerous obstacles have been encountered by medical care providers in developing patient safety solutions. Leape and Berwick [21] identified five main challenges in enhancing patient safety: (i) modern healthcare technology's far higher complexity than other industries, (ii) medicine's continuous commitment to individuals, professionals and autonomy, (iii) fear of physicians and patients, (iv) lack of leadership, and (v) paucity of measures. These challenges need to be tackled first before adopting any practice to enhance safety.

\subsection{Applications of RFID in Healthcare Environment}

Although applying RFID in healthcare sector is not new, it is still in the infant stage. The focus on RFID applications in healthcare industry is increasing due to the potential benefits such as the ability to keep track of the medical devices and equipment used [22]. It is believed that RFID is capable of improving the downside and inefficiency of the current operations through enhancing communication, monitoring, identification and ontime tracking, etc. [23]. As a result of the positive impacts and the capabilities of improving the current service performance, many medical service providers have shown interest in applying RFID. Numerous pilot tests of RFID-based healthcare solutions [5], addressing issues such as managing and tracking medical devices, monitoring and identifying patients, ensuring that the right patient is given the right medication, and preventing the use of counterfeit medicine, have been reported in the literature. Table 1 summarizes the applications of RFID in healthcare reported in the literature.

To the best of the authors' knowledge, most of the current studies and applications are proof-of-concept in nature, whereas this paper extends the study to investigating the RFID implementation and maintenance in an actual healthcare environment. Although several studies $[9,13]$ have identified critical factors for successful RFID adoption, they mainly focused on the deployment pre-requisites, rather than considering issues related to implementation and maintenance (and not in the surgery procedures perspective). The contribution of this paper is that it adopts real-life surgery scenarios/procedures to inquire about the implementation approach and lessons learnt from an RFID project in a healthcare environment. 
Table 1. Summary of literature reporting applications of RFID in healthcare

\begin{tabular}{|c|c|}
\hline & Applications \\
\hline Tracking & $\begin{array}{l}\text { - } \quad \text { Locating wandering patients and misplaced equipment [24] } \\
\text { - Tracking staff [25] } \\
\text { - Tracking patients and objects inside and outside the } \\
\text { hospitals }[9,26] \\
\text { - } \quad \text { Tracking patient files [27] } \\
\text { Ensuring patient receives blood transfusion of the correct blood } \\
\text { type [28] }\end{array}$ \\
\hline $\begin{array}{l}\text { Identification and } \\
\text { verification }\end{array}$ & $\begin{array}{ll}\text { - } & \text { Drug identification [29] } \\
\text { - } & \text { Identifying the nearest unused equipment and resources [25] } \\
\text { - } & \text { Patient identification }[8,30] \\
\text { - } & \text { Product authentication [28] } \\
\text { - } & \text { Monitoring drug administration [31] }\end{array}$ \\
\hline Sensing & $\begin{array}{l}\text { - } \quad \text { Monitoring of activities of daily living [32] } \\
\text { - } \quad \text { Monitoring in home medication-intake [33] } \\
\text { - } \quad \text { Monitoring temperature, humidity, motion, acoustic [34] } \\
\text { oxygen saturation, etc. [32] }\end{array}$ \\
\hline $\begin{array}{l}\text { Warning and } \\
\text { prevention }\end{array}$ & $\begin{array}{l}\text { - Detecting errant blood transfusions [24] } \\
\text { - Warning when surgical sponges are left in wrong places [24] } \\
\text { Warning when drugs and patient are mismatched, when patients } \\
\text { - } \quad \text { Imprer restricted area, and when patients leave the ward [35] } \\
\text { - } \quad \text { Preventing theft by warning against unauthorized movement of } \\
\text { equipment [25] }\end{array}$ \\
\hline Other applications & $\begin{array}{l}\text { - Real-time access/update of patients' profile and medication } \\
\text { records by medical staff }[27] \\
\text { - } \quad \text { Part of the electronic health record }[28,36]\end{array}$ \\
\hline
\end{tabular}

\section{ANALYSIS OF THE CURRENT WORKFLOW}

This part of research was approved by the research ethics committee concerning protection of human subjects in research. This study adopts the conventional procedure of systems engineering development [15]. At the beginning, ten surgeons and ten nurses were interviewed individually to understand the existing processes that start from the moment when the nurse performs pre-surgery procedures at the patient's bedside till the time when the patient is moved back to the ward. These workflows can be divided into three groups of procedures, namely, pre-surgical, intra-surgical, and post-surgical procedures.

\subsection{Pre-Surgical Procedures}

The patient's identity is checked manually at present. This process is rather timeconsuming for nurses to check each paper-based medical records and medical letters of 
individual patient. Furthermore, all the collected documents are stored in a plastic bag which may be misplaced. For each service provision (e.g., blood drawing), complicated checking is performed several times. Other than checking patient information, counting materials is performed manually which is also time consuming and may delay the start of a surgery.

\subsection{Intra-Surgical Procedures}

At the beginning of a surgery, the nurse, surgeon and anesthetist routinely take time to ask the patient for his/her identity, explain the procedure and anesthesia to the patient. Also, writing extra materials and equipment on the whiteboard may induce medical errors since the handwriting may confuse the nurses when counting the materials and equipment used. It is also time-consuming because the medicines and equipment used often have long names that take time to write down. It takes two nurses to count the materials and equipment used. The counting is performed three times during the suturing operation.

\subsection{Post-Surgical Procedures}

The nurse checks the patient's identity manually by reading the information shown on the bracelet and the documents of the patient. It is an inefficient practice involving high risk of medical errors.

\subsection{Areas for Improvement}

\subsubsection{Tracking of Patient is Non-Existent}

Patients in the hospital are not tracked. The bracelet worn by a patient is solely used to identify the patient. Tracking patients is essential to prevent patients from entering wrong zones that may cause medical errors.

\subsubsection{Identifying Patient Based on the Information Printed on the Bracelet}

Limited information is printed on the bracelet. Other information, such as the patient's medical records, is stored separately. Reading the information on the bracelet and other documents related to the patient at the same time is time-consuming and prone to error.

\subsubsection{Redundancy in the Checking Process}

The patient's identity is checked manually five times before the surgery begins. It is possible to minimize the checking time and reduce the workload of nurses, so that the surgery can commence with minimal delay.

\subsubsection{Manually Recording the Materials and Equipment}

Before their use, the quantities and names of materials and equipment needed for the surgery are written down manually on a whiteboard.

\subsubsection{Triple Checks Performed by Two Nurses}

The quantities of materials and equipment used are checked three times while the incision is being sutured. 


\subsubsection{Bracelet removed by Patients}

The patient may remove bracelet at any point after discharge from the operation room. Someone else may take the bracelet for improper use if the patient does not handle the removed bracelet properly.

\subsubsection{Retention of Instruments and Materials in Patients' Body}

According to a Hospital Authority report published in 2011 [5], "retain instruments/ material after surgery/interventional procedure" is the most frequently occurring cause of medical errors. Therefore, tracking of materials and instruments used in surgery is imperative.

\subsubsection{Incorrect Operations Involving Wrong Patients or Body Part}

The second frequent occurrence of medical error relating to surgery is the "surgery/interventional procedure involving the wrong patient or body part". Therefore, accurate identification of patients is critical.

\section{ARCHITECTURE OF THE RFID-BASED SURGERY MANAGEMENT SYSTEM}

An RFID-based Surgery Management System has been developed to address the above issues with a modular structure. Each module is designed to perform specific functions. By integrating RFID tags, readers with antennas, Personal Digital Assistant (PDA), computers, Wireless Access Point (WAP), middleware and databases (Figure 1), the modular structure can perform three main functions namely, identification of medical assets (such as patients), real-time tracking of medical equipments/assets, as well as instant alert and warnings.

The RFID-based Surgery Management System has two mechanisms to capture data. The first mechanism serves as a docking station or gateway (i.e., the RFID reader and

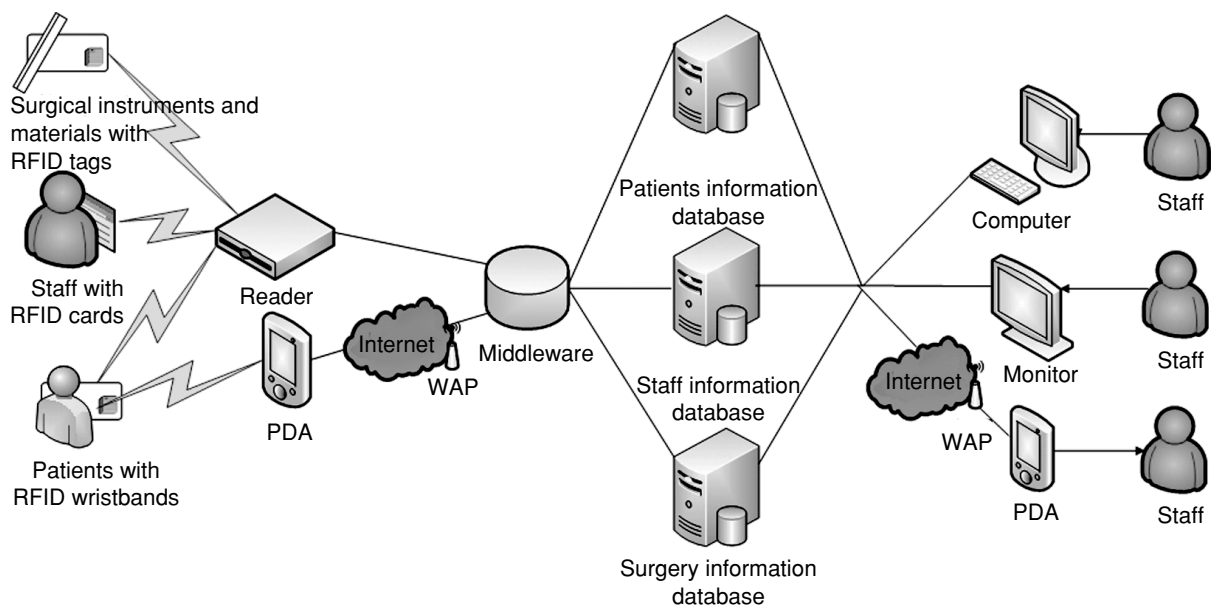

Figure 1. System architecture of the RFID-based Surgery Management System. 
antennas, installed on a table or mounted on the entrance door). It is mainly used for registering RFID tagged surgical instruments and materials, as well as monitoring the movement of patients in a healthcare facility. When the readers are ready, they emit signals to the surroundings through the antennas. If an RFID tagged item is nearby, the tag will modulate the signals so as to embed its serialized number (for unique identification/representation of the tagged entity) before sending the modulated signals back to the antenna and thus the readers. The second mechanism is for item tracking purposes, especially in high mobility situations. An RFID reader is embedded in a PDA (i.e., RFID handheld reader) that can be used to collect information on patients (e.g., in surgery rooms or wards) via reading the patient's RFID tagged wristband. The personin-charge of the surgery will also use the RFID-enabled PDA to read his staff card. The captured data are transmitted to the middleware via WAP. Such data will be processed by the middleware which in turn will forward the processed data to a database for storage. Through the use of computers and PDAs, authorized users can retrieve, edit and update the captured data.

In the current system, RFID tag is encoded with serialized numbers that conform to EPCglobal Class 1 Generation-2 Ultra-high Frequency (UHF) Air Interface Protocol Standard (termed "Class 1 Gen 2" for short in this paper). Such standard is selected because of its growing adoption for item-level identification in the globalized market [37]. The standard limits operations within the $860 \mathrm{MHz}$ to $960 \mathrm{MHz}$ frequency range. Based on the findings of our previous Electromagnetic Interference (EMI) tests [5], all the RFID systems are placed at least $30 \mathrm{~cm}$ away from a medical device to avoid interference problems. Table 2 summarizes the RFID settings in the RFID-based Surgery Management System.

With the above specifications, the RFID-based Surgery Management System comprises three modules, namely, Patients and Staff Identification Module, Patients and Staff Tracking Module, as well as Medical Equipment and Materials Counting Module. Details of each module are discussed below.

\subsection{Patients and Staff Identification Module}

4.1.1. Tagging of Patients and Staff

Each patient wears an RFID-embedded wristband which stores information for identification of the bearer. It is used to confirm the identity of patients at critical

Table 2. RFID system and software summary

- $\quad$ Reader: Alien ALE-9800 RFID Reader

- Antenna: 900MHz antennas for one doorway

- Handheld Reader: CS101 Handheld RFID Reader

- Tag: EPCglobal UHF Class 1 Generation-2 (Passive tag)

- Middleware: Readers are connected to a laptop that runs a small custom-written program 
stages during the entire period of hospitalization, for instance, before commencement of a surgery. When a patient is discharged from the hospital, the wristband has to be returned to the hospital. The returned wristband can be reused by deleting all information stored in the tag. Information such as patient's name, identification number, age, gender and the name of the doctor in charge, depending on the storage size of the RFID tag, is stored to provide necessary information for identification (Figure 2). Large volumes of information such as medical history, family medical history, current drug charts and usages, drug allergies, laboratory results and blood type, etc., are stored in the patients' record in a database. Furthermore, each staff in the hospital is required to carry an RFID-embedded card [36]. Data such as staff's name, identification, names of patients currently under care, schedule for operation, etc., are stored in the staff member's record in the database. A photo of the staff member is also shown on the card which will be used for checking into the system and access control.

\subsubsection{Identification of Patients and Staff}

Identification of patients and staff will take place at the ward, waiting room, surgery room and recovery room. Nurses are equipped with a handheld reader to retrieve the data stored in a tag, and a PDA embedded with an RFID reader to read the information stored in the wristband. Fixed readers can also be located at the entrances of waiting room, surgery room and recovery room and at bed side. A computer is linked to the

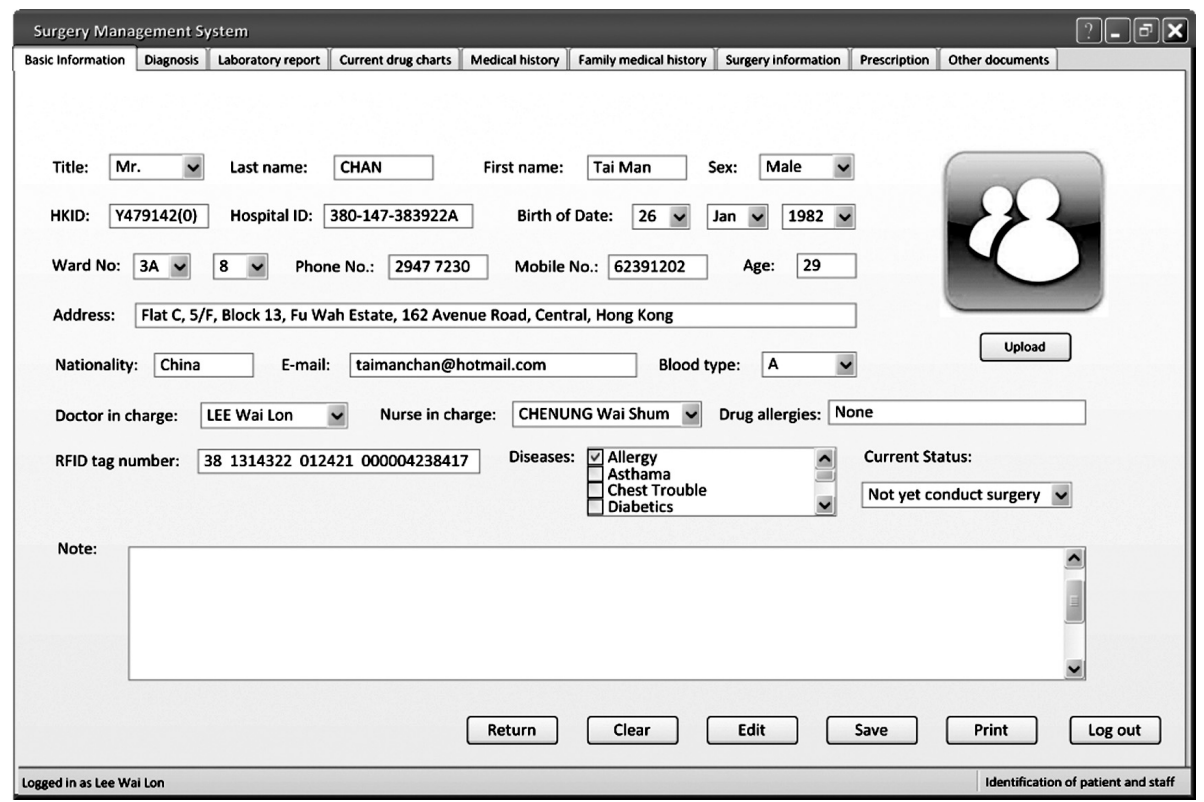

Figure 2. Sample basic information (fictitious) retrieved by scanning the RFIDembedded wristband. 
patient information database enabling the staff to retrieve detailed information of the patient. Moreover, RFID access control ensures that only authorized staff can gain access to the waiting room, surgery room and recovery room. Staff use their RFIDembedded staff card to enter those places.

\subsection{Patients and Staff Tracking Module}

\subsubsection{Tracking in Surgery Room}

The RFID-based Surgery Management System enables staff to monitor the presence and absence of patient and staff in the operation room. By reading the patient's RFIDembedded wristband, the fixed RFID readers located at the entrance of the surgery room can detect everyone entering the room. Figure 3 is a screen dump of the user interface showing the identity (fictitious) of people in the room, where green lights in the display indicate the presence and red lights indicate the absence of specified assigned persons. When an assigned person has not yet arrived, the system automatically sends a short message to alert that person. On the other hand, if a person not on the assigned list is in the surgery room, the system will also alert the users. Warning will be displayed on the monitor to draw user's attention to perform appropriate procedures to ensure that only assigned persons are in the venue.

\subsubsection{Existing and Previous Location of Patient and Staff}

Staff can trace the movement and track the current location of a patient as every time a patient enters or leaves a place with a reader mounted access, the event (e.g., date, time

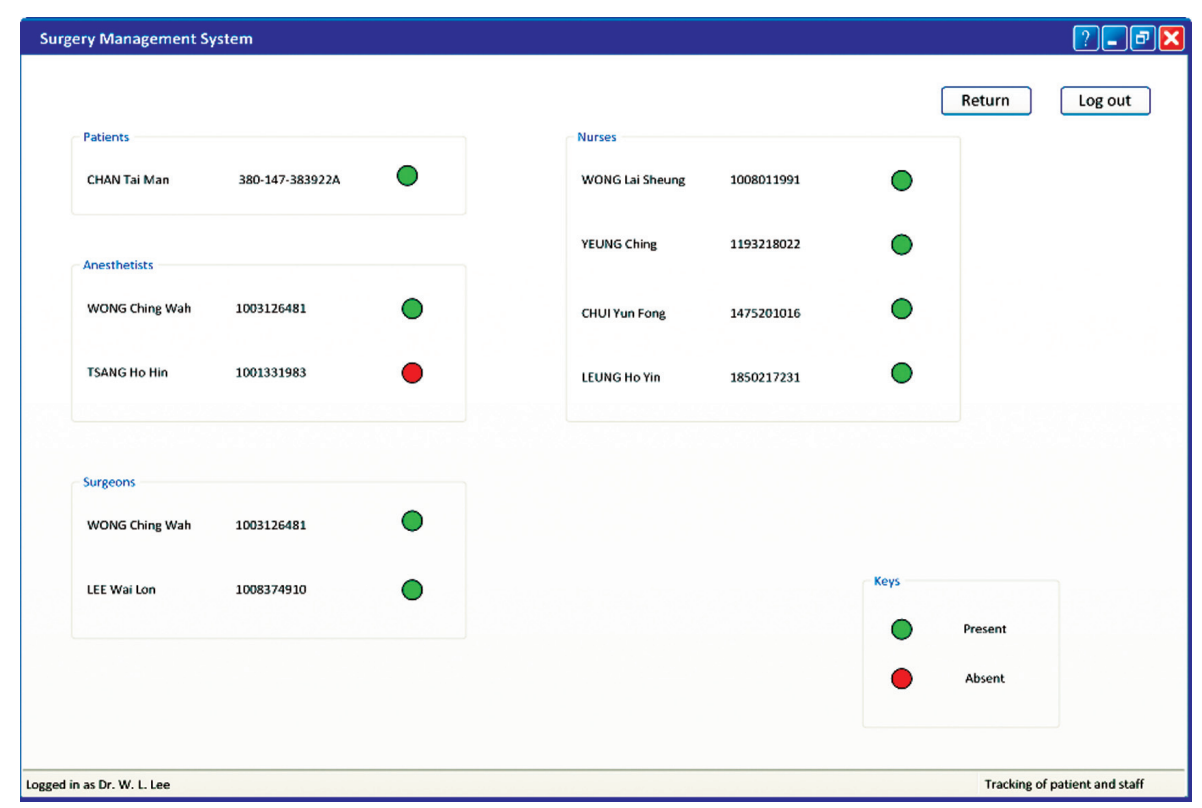

Figure 3. Attendance of patient and staff (fictitious identity). 


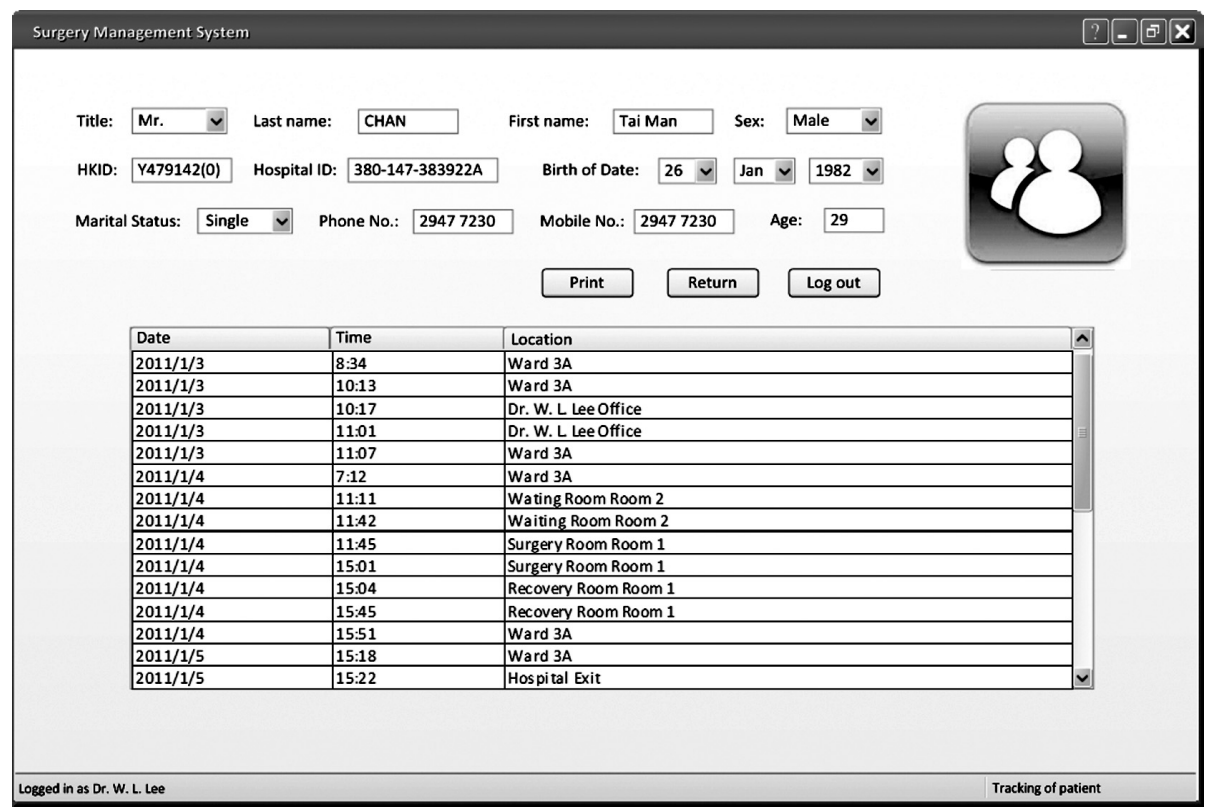

Figure 4. Movement information of a patient (fictitious).

and location) along with the identity of the patient is recorded automatically. Figure 4 shows the system's user interface that traces the movement of a patient (fictitious) in a hospital.

\subsection{Medical Equipment and Materials Counting Module} 4.3.1. Entering General Information of Surgery

Staff needs to enter the type of surgery, room number, date of surgery performed and surgery identification number first (Figure 5). Such information can be used as keys for future retrieval of the surgery or for classification of surgeries.

\subsubsection{Recording Materials and Equipment}

Before performing a surgery, the materials and equipment are placed on a tray embedded with a reader. The system records the type of materials and equipment along with the numbers of their RFID tags. Types of materials and equipment with their unique RFID numbers are then shown on the system (Figure 6). Any additional material or equipment used during the surgery will first be placed on the tray for recording purposes before use. For bulky medical equipment, an RFID handheld reader is employed to read the tag.

\subsubsection{Counting Materials and Equipment}

After the surgery and before suturing, all the repacked materials and equipment are placed back on the RFID-reader-embedded tray. For bulk medical equipment, an RFID handheld reader is used to scan the tag. For all the tagged materials and equipment re- 


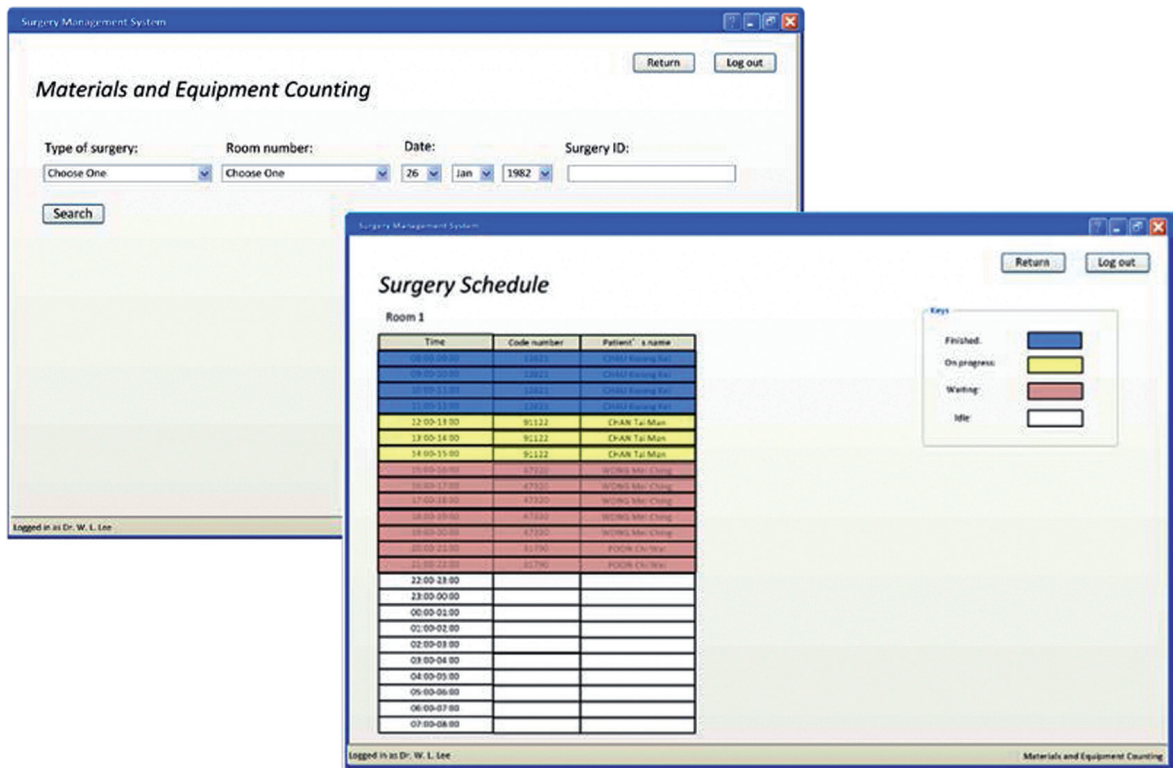

Figure 5. Materials and equipment counting.

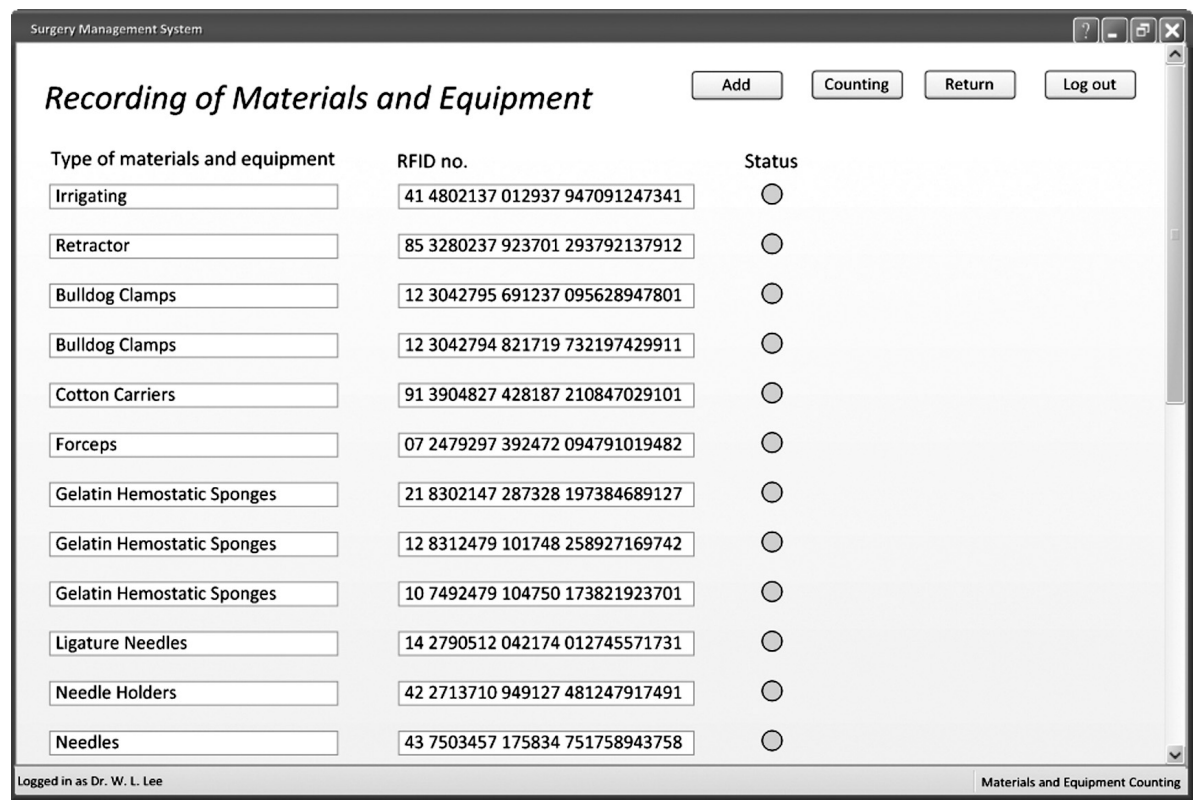

Figure 6. Record of surgical equipment and materials used. 
registered after the surgery, the status buttons to the right of these items on the user interface (Figure 6) will show green, while a red status button indicates that the tagged (used) item has not yet been accounted for.

4.3.4. Medical Equipment and Materials Tracking

When any material or equipment is missing, users can use the RFID-system to perform a tracking procedure. A handheld RFID reader can detect whether the missing item is retained in the patient's body after a surgery, or elsewhere in the surgery room.

\subsection{Improved Workflow}

The RFID-based Surgery Management System can optimize the workflow by eliminating redundant checking and other non-value-added activities because it is expected that RFID can increase accuracy of item identification. The optimized workflow can enhance patient safety, reduce the number of medical errors and thus improve efficiency of the operation.

\subsubsection{Pre-Surgical Procedures}

Figure 7 shows the pre-surgery workflow. Before the surgery, a nurse uses an RFIDreader-embedded PDA to identify the patient. If the right patient cannot be identified, the nurse will $\log$ into the system to locate the patient. After the right patient's identity is confirmed, the nurse briefs the patient on the surgical procedures the patient will receive. The nurse then asks the patient to digitally sign the consent form displayed on the PDA.

As the patient arrives at the waiting room, readers located at the entrance automatically detect the patient's RFID bracelet and the patient's information is shown on the computer screen at the workstation. A nurse uses PDA to double-check the patient's identity. After the patient's identity is re-confirmed, the nurse updates the status of patient to "In waiting room". Otherwise, the nurse can use the tracking function to locate the patient.

When the patient is transferred to the surgery room, the readers at the entrance register the patient's arrival. A nurse uses the "Attendance of patient and staff" function of the system to reconfirm the patient's identity, and tracks the right patient's location if the patient's identity is mismatched. After reconfirming the patient's identity, the nurse checks the patients' information database to make sure that the appropriate consent form has been signed properly by the patient, before the patient's status is updated to "In surgery".

\subsubsection{Intra-Surgical Procedures}

As depicted in Figure 8, the nurses, surgeons and anesthetists identify the patient by information displayed on the monitor, and explain the procedures and the anesthesia to the patient. The patient's identity is then checked again by another staff. If the patient's identity does not match, the tracking module will be employed to find the right patient. Patient's identity check will be repeated at the waiting room. After the patient's identity is re-confirmed and the surgical procedures and anesthesia are explained to the patient, the nurse will log into the "Recording the materials and equipment used" module to record the equipment and materials to be used in the surgery. During the surgery, all 
(a)

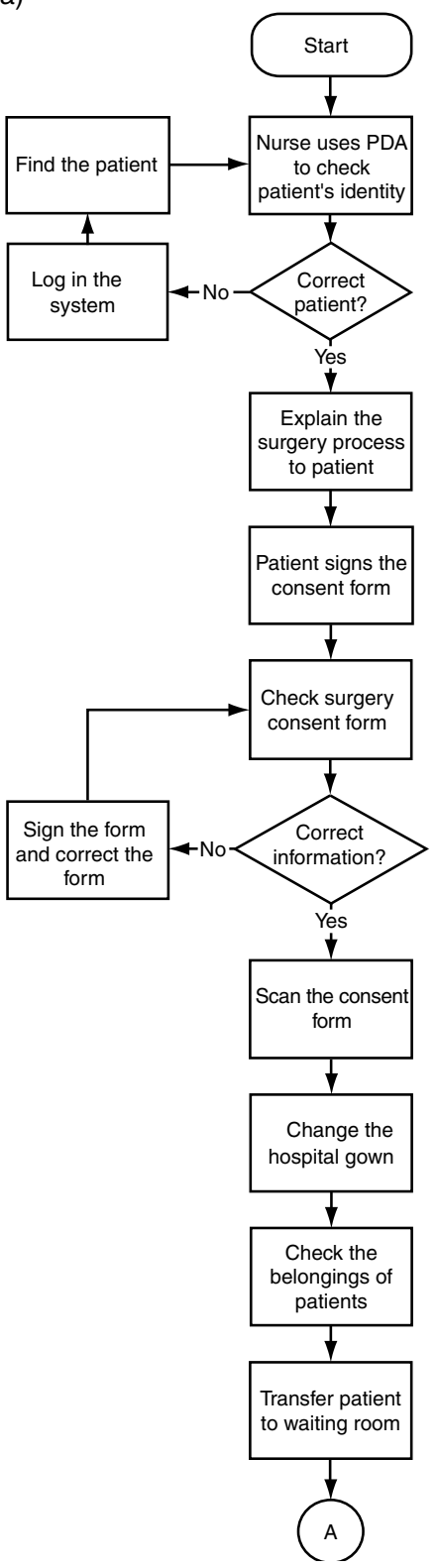

(b)

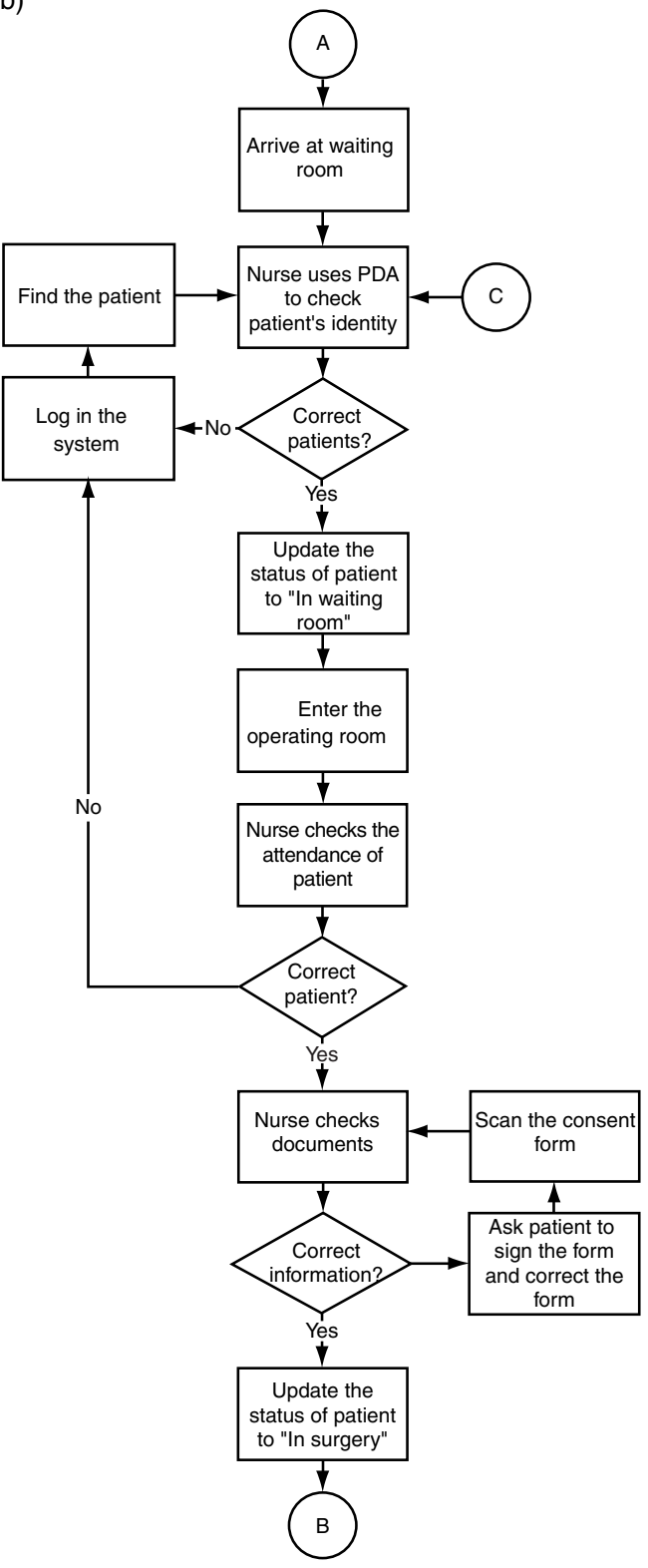

Figure 7. Improved workflow before surgery. Procedures before (a) and after (b) transferring patient to the waiting room. "A" indicates connection between Figure 7(a) and Figure 7(b). "B" indicates connection between Figure 7(b) and Figure 8(a). "C" indicates patient information database. 
(a)

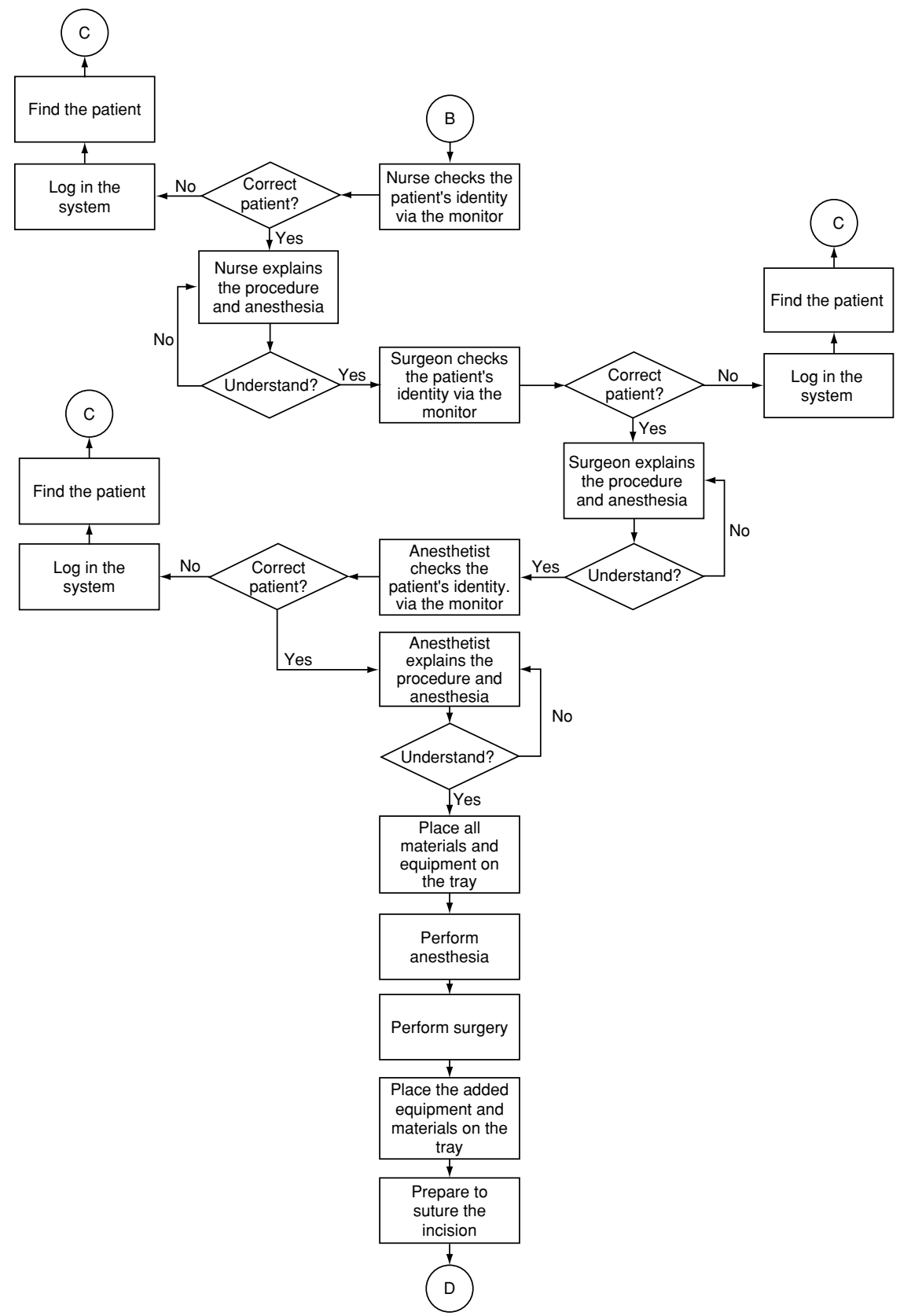

Figure 8. (Continued) 


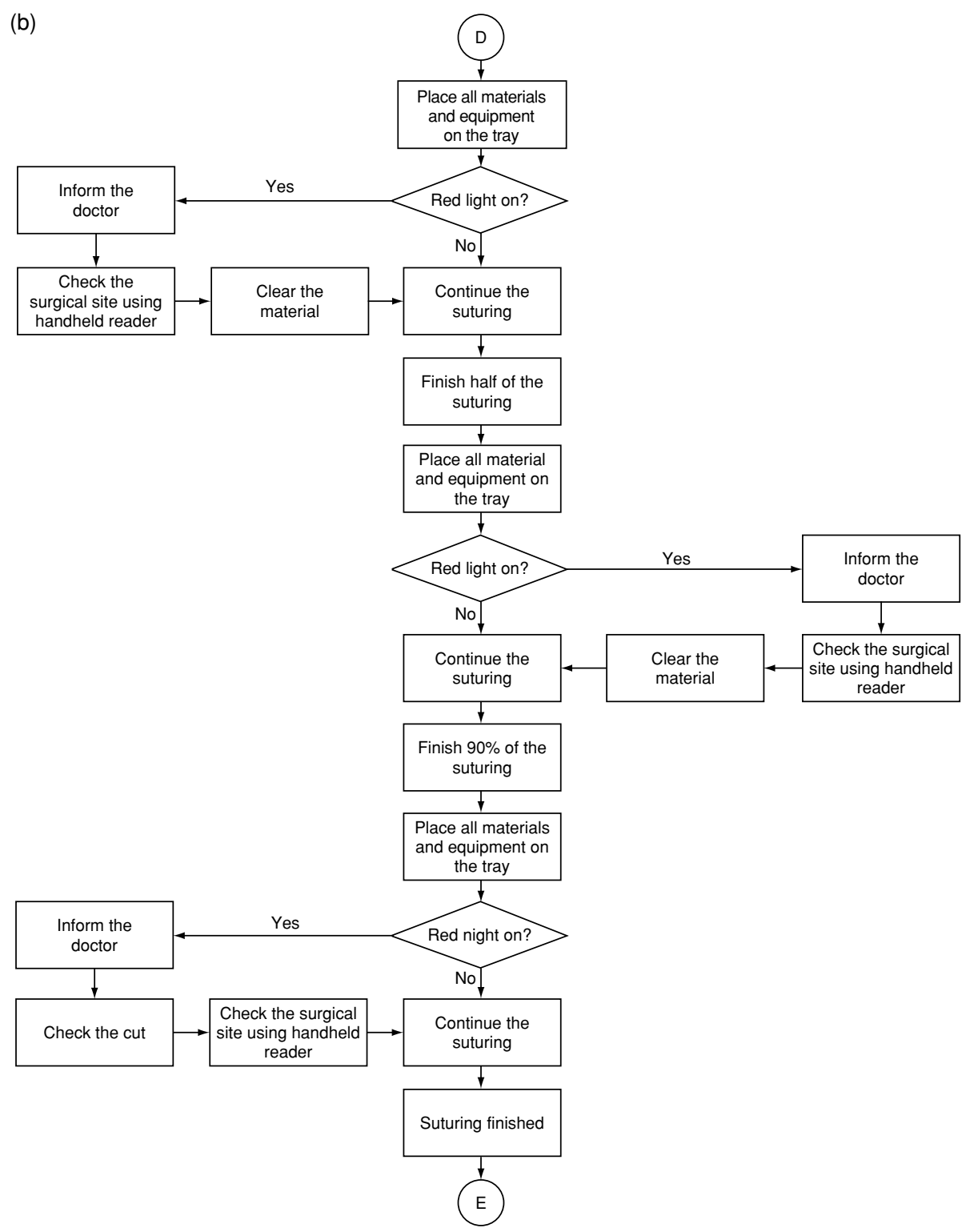

Figure 8. Improved workflow during surgery. Procedures before (a) and after (b) preparing the materials to suture the incision. "B" indicates connection between Figure 7(b) and Figure 8(a). "C" indicates patient information database. "D" indicates connection between Figure 8(a) and Figure 8(b). "E" indicates connection between Figure $8(\mathrm{~b})$ and Figure 9. 
additional materials and equipment used will be registered by placing on the RFIDreader-embedded tray first before use.

Near the end of the operation, before suturing the cut, the nurse will place all the equipment to be repacked on the RFID-reader-embedded tray to check if the identity and quantity of those materials and instruments match the recorded items used in the surgery. If the display shows any red light, indicating that an item used is not on the tray, the nurse will inform the surgeon who will check the surgical site using a handheld reader to detect if the missing item is in the patient's body. After clearing the retained item from the body, suturing continues. This procedure will be repeated twice when the suturing is half and around $90 \%$ complete, respectively.

\subsubsection{Post-Surgical Procedures}

As shown in Figure 9, after the surgery is completed, the patient is transferred to the recovery room. Readers at the room entrances record the move of the patient from the operating room to the recovery room. The nurse then updates the status of the patient to "In recovery room". After the patient wakes up and the condition becomes stable, the nurse in the recovery room contacts the nurse in the ward to arrange for transferring the patient. The nurse from the ward uses an RFID-reader-embedded PDA to identify the patient. After the identity is confirmed, the patient is transferred back to the ward with his/her status updated to "In ward". If the patient's identity does not match, the nurse logs into the system to track the right patient's location.

\section{DISCUSSIONS}

\subsection{Comparison of Existing and Improved Workflows}

The proposed RFID-based Surgery Management System will significantly change the existing workflow, as discussed below.

\subsubsection{Identification of Patients}

In the existing workflow, a nurse identifies a patient by comparing the information in documents and the bracelet worn by the patient. Since neither the documents nor the bracelet show any photo in the current system, the nurse can only compare the name and Hong Kong Identification Number (HKID) printed on both items in order to confirm patient's identity. The proposed RFID-based system will afford the nurse to use PDA to retrieve the patient's data by scanning the patient's wristband. The photo stored in the patient's record will enable the nurse to confirm patient's identity.

\subsubsection{Signing of Surgery Consent Form}

Surgery consent form is signed manually by the patient. The RFID-based system allows most of the paper work replaced by electronic record, thus reducing the risk of losing those papers and the time used to search and replace the misplaced documents.

\subsubsection{Search for Patients}

When the nurse finds that the patient is not the right one, the nursing staff will need to find the patient without clue. With the use of the RFID-based system, they can simply 


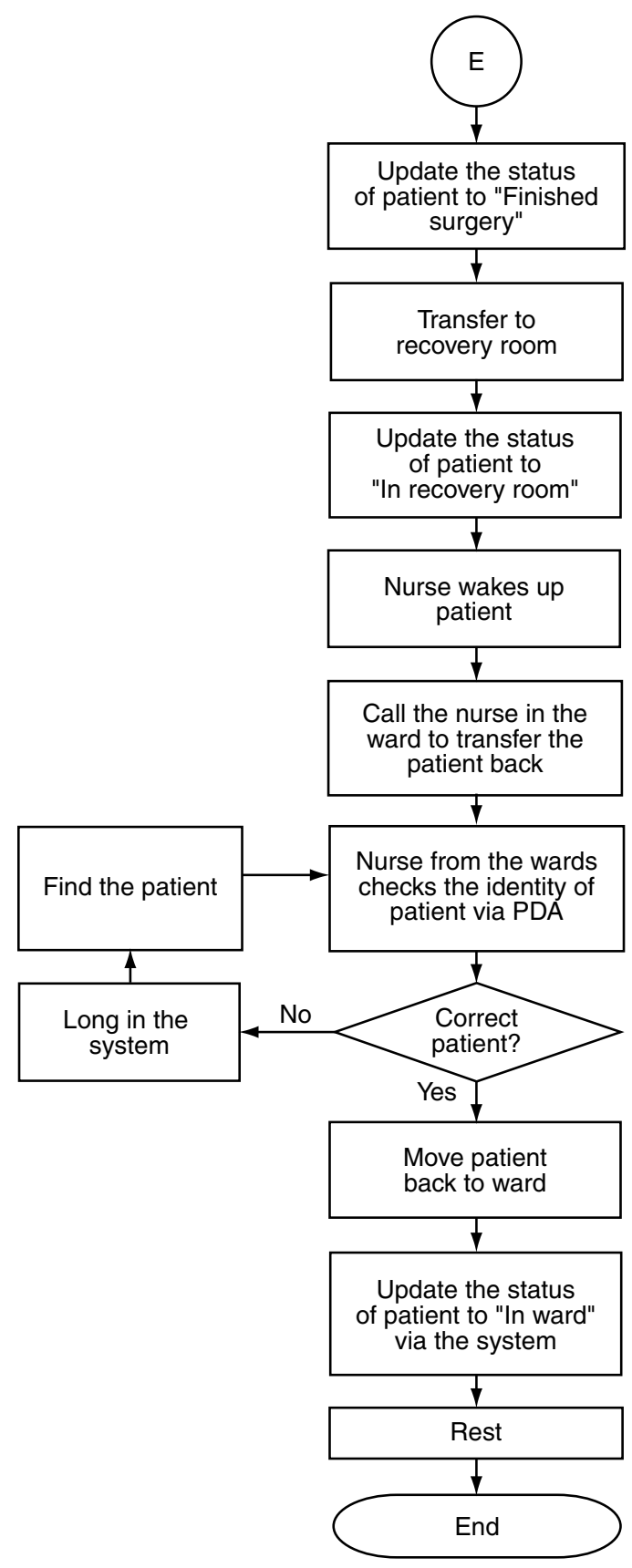

Figure 9. Improved workflow after surgery. "E" indicates connection between Figure 9 and Figure 8(b). 
retrieve information stored in the database to find the location where the patient was most recently in order to narrow the search area.

\subsubsection{Repeated Checking Process}

The patient's identity is currently checked five times before performing a surgery. With the RFID system, only two checks are required in the operation room where three checks are otherwise involved. Since it is expected that using the system to identify a patient is more efficient and reliable, the number of checks can be reduced.

\subsubsection{Recording of Surgical Items}

In the current procedure, surgical items are written on the whiteboard by nurse. With the RFID system, the nurse only needs to place the to-use items on the RFID readerembedded tray for registration.

\subsubsection{Counting the Repacked Surgical Items}

Two nurses are involved in counting the repacked surgical materials and equipment in the current procedure. In the RFID system, only one nurse is required to place these items on the tray. Alerts will be triggered automatically to draw users' attention when any item is missing.

\subsection{Improvements of Adopting the RFID-Based System}

The current RFID-based Surgery Management System can bring forth the following improvements, although all these are subject to substantiation through prospective clinical studies.

\subsubsection{Reducing Medical Errors and Improving Patient Safety}

By implementing the RFID-based system, patient safety can be greatly enhanced and medical errors can be significantly reduced. Identification of patient would become easier and more reliable because relevant information can be retrieved from the RFID wristband and database. Staff will be alerted when a wrong patient or staff enters the operating room. Thus, performing a surgery on a wrong patient or on a wrong part of the patient (due to poor handwritten information on paper records) can be avoided. The RFID system also automatically counts the surgical instruments and materials, and identifies any missing item. With less human involvement, fewer human errors are expected.

\subsubsection{Reducing Staff Workload}

With the help of the RFID system, many manual operations by staff, such as checking patient's identity, finding the missing patient, recording and counting surgical materials and equipment, are either automated or facilitated. This allows staff to better focus on providing patients with higher quality services.

\subsubsection{Cost Saving Due to Reduced Medical Errors}

Enormous costs will be involved to remedy medical errors. For example, extra costs for having X-ray to detect the location of items retained in the patient's body, remedial 
surgery to remove the retained items, potential lawsuit from the patient, and the knock on effect of delaying other surgeries, etc. The RFID system reduces the chance of medical errors, thus saving the cost due to medical errors.

\subsubsection{Improving Public Confidence in Hospitals' Service Quality}

Confidence of the public in hospitals is seriously affected by a series of medical errors in Hong Kong. By employing the RFID system, the number of medical errors would be significantly reduced, and the public's confidence in the medical services provided by the hospital could be restored or enhanced.

\subsection{Critical Elements for Considerations}

Several critical elements are identified from the implementation of an RFID-system in a Hong Kong public hospital. They are grouped into four dimensions: technical, management, capital, and privacy.

\subsubsection{Technical Dimension}

- Security of information

Encryption is important in healthcare information systems in preventing unauthorized access to patient information. Besides, password is needed for staff to access the system. These measures can protect privacy of the patient and staff so that their information will not be used for unintended purposes.

\section{- $\quad$ Electromagnetic interference}

The radio waves emitted by the antenna may interfere with other medical equipment. The affected equipment may malfunction, thereby endangering the life of patients it supports or monitors. While the system we deployed in the reference site passed the electromagnetic interference (EMI) test, the conditions may vary from one site to another; therefore, testing and experiments need to be conducted to ensure proper functioning of other medical devices on deployment of the system.

- Reliability

Communication errors between tag and reader, such as false reads and misreads, should be minimized so as to maintain a high level of tag reading reliability. Various solutions for management of RFID data, such as anti-collision and efficient error-correcting code scheme [38, 39], should be considered to enhance consistent reliability performance of the system. Furthermore, on-site analysis is an essential part of RFID implementation to ensure system performance. Two sets of tests, namely Tag Placement Analysis and Interrogation Zone Analysis [40], were conducted to identify the optimal placement of RFID tags on equipment, and to assess the profile of readability performance at the sites of system deployment, respectively. 


\subsubsection{Management Dimension}

- $\quad$ Training

Training is one of the key factors affecting the success of RFID projects. This is particularly true in the healthcare environment, as most of the healthcare professionals do not have the expertise of operating novel information technology systems. In our study, seminars were conducted to introduce the basic concepts of RFID technology and workshops were organized to provide hands-on practice of using RFID. This can enhance users' confidence in using the system.

- Top management support

Table 3. Quantitative benefits analysis on quality of service comparing barcode and RFID

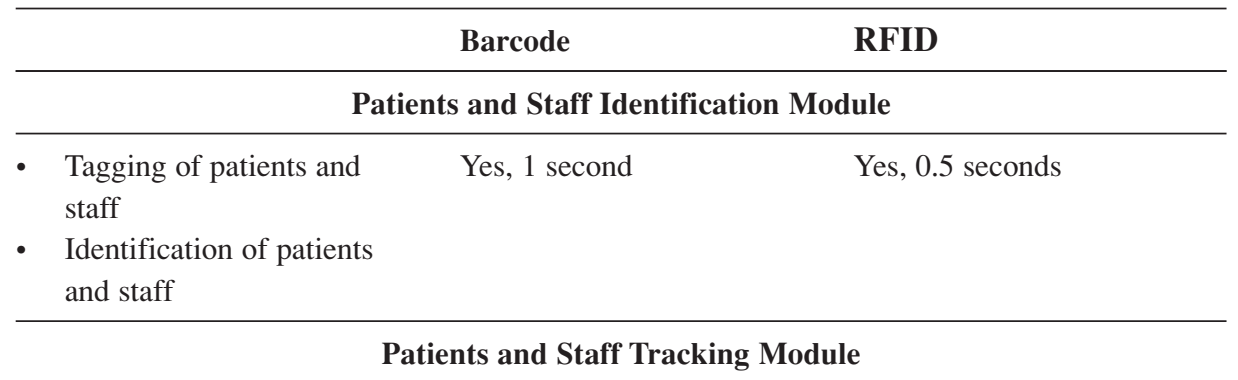

- Identification of patients and staff

- Determining the current and previous locations of patient and staff
Yes, 5 seconds Yes, 0.5 seconds

(as barcode cannot automatically capture the information, the user has to carry an RFID handheld reader to read the barcode)

No

Yes

\section{Medical Equipment and Materials Counting Module}

- Enquiry of surgery
No

Yes, 40 seconds to 1.5 minutes

(as items need to be scanned individually)
Yes

Recording of materials and equipment to be used

- Counting of materials and equipment to be used

- Medical equipment and materials tracking 
Resistance to change is one of the human factors jeopardizing the success of RFID projects. In order to facilitate deployment of the RFID system, top management support is important to motivate staff to adopt the new workflow. Furthermore, objectives of the project and the implementation plan should be clearly communicated to all stakeholders in the organization so as to lower people's concerns and doubts.

\subsubsection{Capital Dimension}

The initial cost of implementing the RFID system is substantial. This is particularly true in the case of large hospitals. A sound and well defined Return On Investment (ROI) policy is essential for successful implementation of this type of project. Owing

Table 4. Qualitative benefits analysis on quality of service comparing barcode and RFID

\begin{tabular}{|c|c|c|c|}
\hline & & Barcode & RFID \\
\hline \multicolumn{4}{|c|}{ Patients and Staff Identification Module } \\
\hline & $\begin{array}{l}\text { Tagging of patients and } \\
\text { staff } \\
\text { Identification of patients } \\
\text { and staff }\end{array}$ & $\begin{array}{l}\text { Barcode cannot store } \\
\text { information; it can only store } \\
\text { an identification number } \\
\text { which serves as a key to } \\
\text { retrieve patient information } \\
\text { from a database. }\end{array}$ & $\begin{array}{l}\text { RFID can store much more } \\
\text { information locally and } \\
\text { perform fast retrieval of } \\
\text { medical information } \\
\text { related to the patient. }\end{array}$ \\
\hline \multicolumn{4}{|c|}{ Patients and Staff Tracking Module } \\
\hline & $\begin{array}{l}\text { Identification of patients } \\
\text { and staff }\end{array}$ & $\begin{array}{l}\text { Barcode cannot automatically } \\
\text { register the entry and exit } \\
\text { events because it requires } \\
\text { line-of-sight for detection of } \\
\text { tagged items. }\end{array}$ & $\begin{array}{l}\text { RFID can automatically } \\
\text { register all patients and } \\
\text { staff entering a and exiting } \\
\text { a room. }\end{array}$ \\
\hline & $\begin{array}{l}\text { Determining the current } \\
\text { and previous locations } \\
\text { of patient and staff }\end{array}$ & No & Yes \\
\hline
\end{tabular}

Medical Equipment and Materials Counting Module

- Enquiry of surgery schedule

- Recording of materials and equipment to be used

- Counting of materials and equipment

- Medical equipment and materials tracking
No

Yes

Barcodes can only be read one item at a time (time consuming as there are many items to be scanned in each surgery).
RFID can register multiple items in one scan (i.e., all the tagged items can be read at the same time). 
to the huge investment on RFID hardware (e.g., tags and readers), cost comparison must be performed to support selection of hardware items from different suppliers, or alternative solutions (e.g., barcode versus RFID). In our study, the hospital originally wanted to use barcode instead of RFID in the surgery management system. Based on the findings of site tests and our experience of similar projects, a quantitative analysis and a qualitative analysis on benefits related to the quality of service were conducted to compare the barcode and RFID solutions, as presented in Tables 3 and 4, respectively. All the quantitative data are collected via observations in a Hong Kong Public Hospital during the period from Jan 2011 to May 2011. The analyses indicate that an RFID solution would have a better ROI than a barcode solution in enhancing patient safety in the long run.

\subsubsection{Privacy Dimension}

Patients and staff may have concern that their privacy would be threatened by the RFID system because it will automatically capture their personal information (such as location and event data). An approach to address this issue is to get patients' consent, and to make them understand that the information is used for enhancing patient safety and it will not be used for other purposes without being sanitized first. It is also important to introduce carefully thought-out policies that outline the conditions and restrictions of data use so as to prevent ethical lapses.

\section{CONCLUSIONS}

RFID can be applied to manage surgery processes in public hospitals so as to reduce medical errors. The present case study identifies four main problems in the existing practice: inefficient workflow of surgery, lack of automatic alert when items are retained in patient's body, inability to track patient's movement, and misidentification of patient. Surgical instrument and material retained in patient's body, and performing wrong surgery on patient are the most common serious medical errors relating to surgery. An RFID-based Surgery Management System can address this problem by performing four main functions: (a) to identify patients and staff, (b) to track patients and staff, (c) to automatically record the medical instruments and materials used in the surgery, and (d) to accurately count the repacked (tagged) items after surgery.

The RFID system could improve workflow by facilitating manual tasks and eliminating preventable redo procedures. However, proper testing on the system is essential to ensure successful implementation of the system. It is also important to consider some critical elements in developing and implementing the system.

Before making a commitment to launch the project, a cost-benefit analysis should be conducted. It is expected that the system can help to dramatically improve patient safety and reduce medical errors relating to surgery. Staff workload will also be reduced because most of the time-consuming manual tasks will be automated or facilitated by the system. Moreover, wastes (financial and manpower) caused by medical errors would be dramatically reduced. Lastly, confidence of the public in the services provided by the hospital would be enhanced; with the reputation of the hospital improved, more patient-care income could be generated. Further research needs to focus on challenges 
associated with RFID system implementation, such as efforts involved in checking the integrity of the instruments, possible adverse impact on staff morale, gaining stakeholders' acceptance, high implementation costs, privacy issues, and potential interference with operation of other medical devices.

\section{ACKNOWLEDGEMENTS}

The authors would also like to express their sincere thanks to the Research Committee of the Hong Kong Polytechnic University for providing the financial support for this research work.

\section{CONFLICT OF INTEREST}

The authors indicated no potential conflicts of interest.

\section{REFERENCES}

[1] World Health Organization. 10 Facts on Patient Safety. 2007. http://www.who.int/features/factfiles/patient_safety/en/index.html. Accessed October 12, 2011.

[2] Legislative Council. Legislative Council Panel on Health Services: Mechanism for Handling Medical Incidents in Public and Private Hospitals. 2009. http://www.legco.gov.hk/yr0910/english/panels/hs/papers/hs1109cb2-182-3-e.pdf. Accessed November 1, 2011.

[3] Hospital Authority. Annual Report on Sentinel \& Serious Untoward Events 1 October 2009 - 31 September 2010. 2011. http://www.ha.org.hk/haho/ho/psrm/COPYSESUE_Annual_Report_2011.pdf. Accessed November 5, 2011.

[4] Association of Hong Kong Nursing Staff. Result on the Survey on Medical Human Resources. 2009. http://www.nurse.org.hk/c_index.htm. Accessed November 1, 2011.

[5] Ting SL, Kwok SK, Tsang AHC, Lee WB. Critical elements and lessons learnt from the implementation of an RFID-enabled healthcare management system in a medical organization. Journal of Medical Systems. 2011, 35(4):657-669.

[6] Meiller Y, Bureau S, Zhou W, Piramuthu S, RFID-embedded decision support for tracking surgical equipment. Proc. 44th. Hawaii Int'1 Conf. Syst. Sci. 2011, 1-6.

[7] Chen PJ, Chen YF, Chai SK, Huang YF, Implementation of an RFID-based management system for operation room. Int'l Conf. on Mach. Learn. and Cyber. 2009, 2933-2938.

[8] Chowdhury B, Khosla R, RFID-based hospital real-time patient management system. IEEE/ACIS 6th Int'l Conf. on Comp. and info. Sci. 2007, 363-368.

[9] Wang SW, Chen WH, Ong CS, Liu L, Chuang YW, RFID application in hospitals: a case study on a demonstration RFID project in a Taiwan hospital. Proc. 39th. Hawaii Int'l Conf. Syst. Sci. 2007, 184a.

[10] Su CJ, Shih SC. Building distributed e-healthcare for elderly using RFID and multi-agent. International Journal of Engineering Business Management. 2011, 3(1):16-26.

[11] Ngai EWT, Moon KKL, Riggins FJ, Yi CY RFID research: an academic literature review (1995-2005) and future research directions. International Journal of Production Economics. 2008, 112(2):510-520.

[12] Ting SL, Kwok SK, Tsang AHC, Ho GTS. The study on using passive RFID tags for indoor positioning. International Journal of Engineering Business Management. 2011, 3(1):9-15.

[13] Ahsan K, Shah H, Kingston P. RFID applications: an introductory and exploratory study. International Journal of Computer Science Issues. 2010, 7 (1).

[14] Valentin A, Capuzzo M, Guidet B, Moreno RP, Dolanski L, Bauer P, Metnitz PGH. Patient safety in intensive care: results from the multinational Sentinel Events Evaluation (SEE) study. Intensive Care Medicine. 2006, 32(10):1591-1598.

[15] Uzoka FME. Fuzzy-expert system for cost benefit analysis of enterprise information systems: a framework. International Journal on Computer Science and Engineering. 2009, 1(3):254-262. 
[16] Hübner-Bloder G, Ammenwerth E. Key performance indicators to benchmark hospital information systems - a Delphi study. Methods of Information in Medicine. 2009, 48(6):508-518.

[17] Lyke B. Health Care Reform: An Introduction. CBS Report for Congress, Washington, DC, Congressional Research Service, 2009.

[18] Joint Commission on Accreditation of Healthcare Organization. Hospital National Patient Safety Goals. 2011. http://www.jointcommission.org/assets/1/6/2011_HAP_NPSG_EASYTOREAD_docs_11229.pdf. Accessed September 1, 2011.

[19] Liao PC, Liu L, Kuo F, Jin MH, Developing a patient safety based RFID information system - an empirical study in Taiwan. 2006 IEEE Int'l Conf. on Management of Innovation and Technology. 2006, 585-589.

[20] Zhou W, Piramuthu S. Healthcare process mining with RFID. Lecture Notes in Business Information Processing. 2010, 43(5):405-411.

[21] Leape LL, Berwick DM. Five years after to err is human, what have we learned? Journal of the American Medical Association. 2005, 293(19):2384-2390.

[22] Togt R, Lieshout EJ, Hensbroek R, Beinat E, Binnekade JM, Baker PJM. Electromagnetic interference from radio frequency identification inducing potentially hazardous incidents in critical care medical equipment. Journal of the American Medical Association. 2008, 299(24).

[23] Chao CC, Jen WY, Chi YP, Lin BS, Improving patient safety with RFID and mobile technology. International Journal of Electronic Healthcare. 2007, 3(2):175-192.

[24] Korcok M. Tracking itinerant patients and surgical sponges. Canadian Medical Association Journal. 2009, 180(8):E14-E15.

[25] Booth P, Frisch PH, Miodownik S, Application of RFID in an integrated healthcare environment. 28th IEEE EMBS Ann. Int'l Conf. 2006. 2006, 117-119.

[26] Hakim H, Renouf R, Enderle J, Passive RFID asset monitoring system in hospital environment. 32nd Ann. Northeast Bioeng. Conf. 2006. 2006, 217-218.

[27] Polycarpou AC, Gregoriou G, Dimitriou A, Bletsas A, Sahalos N, Papaloizou L, Polycarpou P, Design and implementation of a Radio Frequency Identification (RFID) system for healthcare applications. 12th Mediterranean Conf. on Medical and Biological Engineering and Computing. 2010, 897-900.

[28] Ashar BS, Ferriter A. Radio frequency identification technology in health care: benefits and potential risks. Journal of the American Medical Association. 2007, 298(19):2305-2307.

[29] Ranky PG. An introduction to Radio Frequency Identification (RFID) methods and solutions. Assembly Automation. 2006, 26(1):28-33.

[30] Tzeng SF, Chen WH, Pai FY. Evaluating the business value of RFID: evidence from five case studies. International Journal of Production Economics. 2008, 112(2):601-613.

[31] Houliston B. Integrating RFID Technology into a Drug Administrating System. 2005. http://www.naccq.ac.nz/bacit/0301/2005houliston_rfid.htm. Accessed August 21, 2011.

[32] Alemdar H, Ersoy C. Wireless sensor networks for healthcare: a survey. Computer Networks. 2010, 54(15):2688-2710.

[33] Ho L, Moh M, Walker Z, Hamada T, Su CF, A prototype on RFID and sensor networks for elder healthcare: progress report. 2005 ACM SIGCOMM Workshop on Experimental Approaches to Wireless Network Design and Analysis. 2005; 70-75.

[34] Virone G, Wood A, Selavo L, Cao Q, Fang L, Doan T, He Z, Stoleru R, Lin, Stankovic JA, An advanced wireless sensor network for health monitoring. Transdisciplinary Conf. on Distributed Diagnosis and Home Healthcare (D2H2). 2006.

[35] Wu F, Kuo F, Liu LW, The application of RFID on drug safety of inpatient nursing healthcare. 7th Int'1 Conf. on Electronic Commerce. 2005, 85-92.

[36] Ting JSL, Tsang AHC, Ip AWH, Ho GTS. RF-MediSys: a radio frequency identification-based electronic medical record system for improving medical information accessibility and services at point of care. Health Information Management Journal. 2011b, 40(1):25-32. 
[37] Due DN, Park J, Lee H., Kim K, Enhancing security of EPCglobal GEN-2 RFID tag against traceability and cloning. 2006 Symp. on Crypt. and Info. Sec. 2006.

[38] Chawathe S, Krishnamurthy V, Ramachandran S, Sarma S, Managing RFID Data. 30th VLDB Conf. 2004, 1189-1195.

[39] Derakhshan R, Orlowska ME, Li X, RFID data management: challenges and opportunities. IEEE 1st Int'l Conf. on RFID. 2007, 175-182.

[40] Kwok SK, Tsang AHC, Cheung BCF. Realizing the Potential of RFID in Counterfeit Prevention, Physical Asset Management, and Business Applications: Case Studies of Early Adopters, Department of Industrial and Systems Engineering, The Hong Kong Polytechnic University, Hong Kong, 2007. 


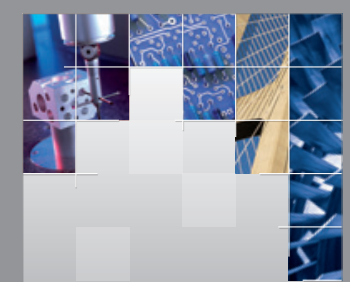

\section{Enfincering}
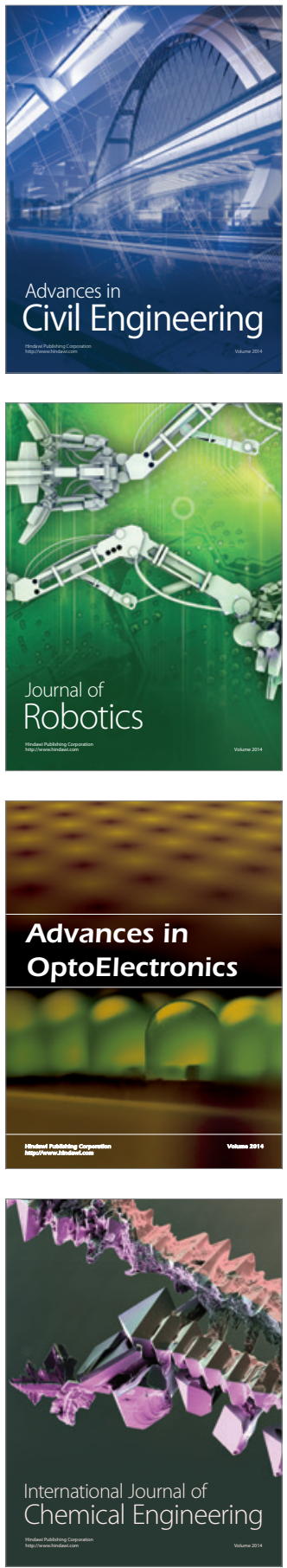

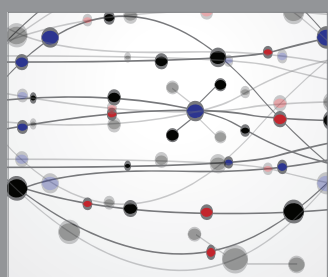

The Scientific World Journal

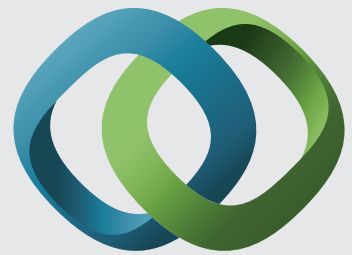

\section{Hindawi}

Submit your manuscripts at

http://www.hindawi.com
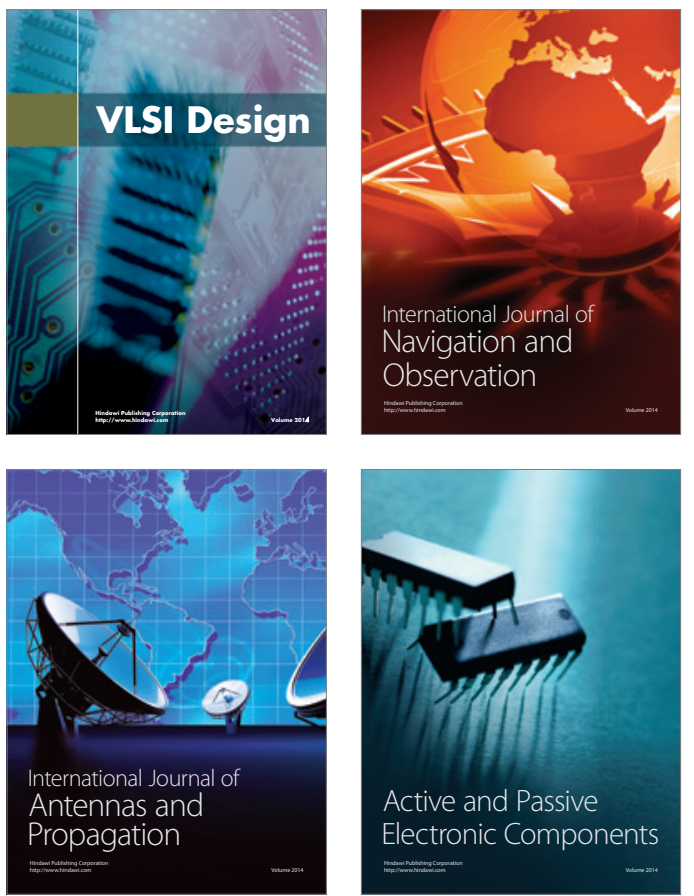
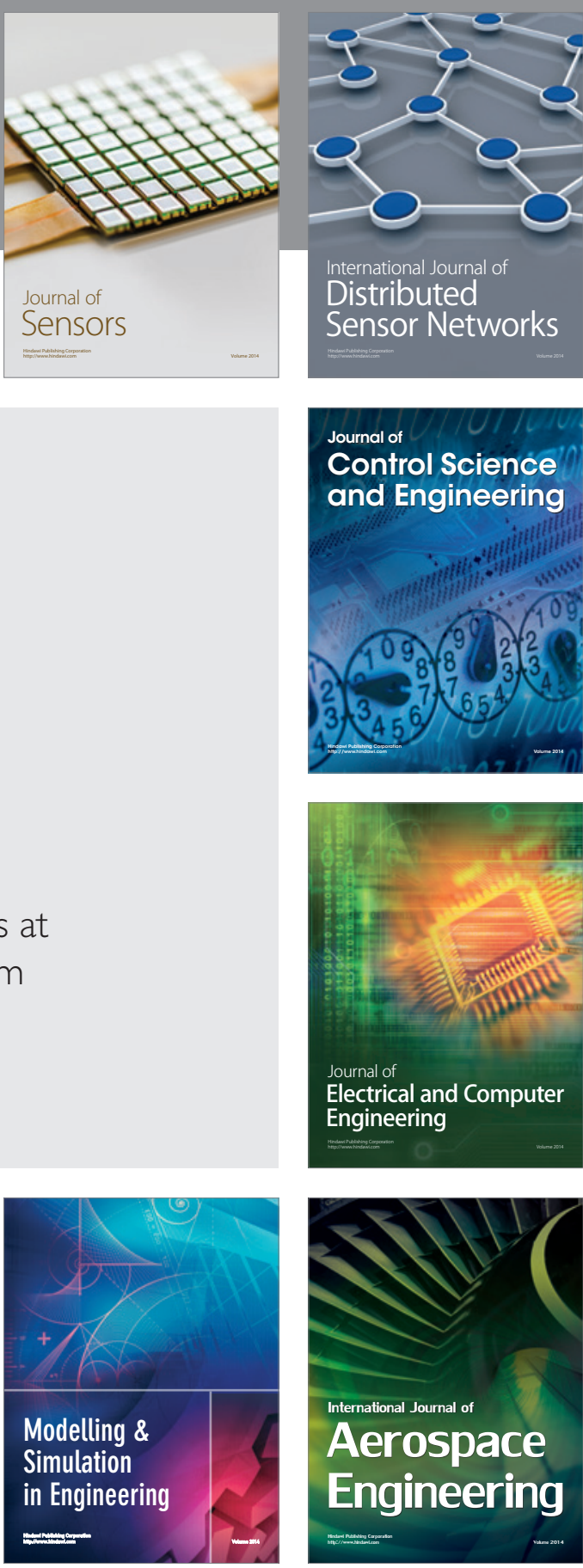

International Journal of

Distributed

Sensor Networks

Journal of

Control Science

and Engineering
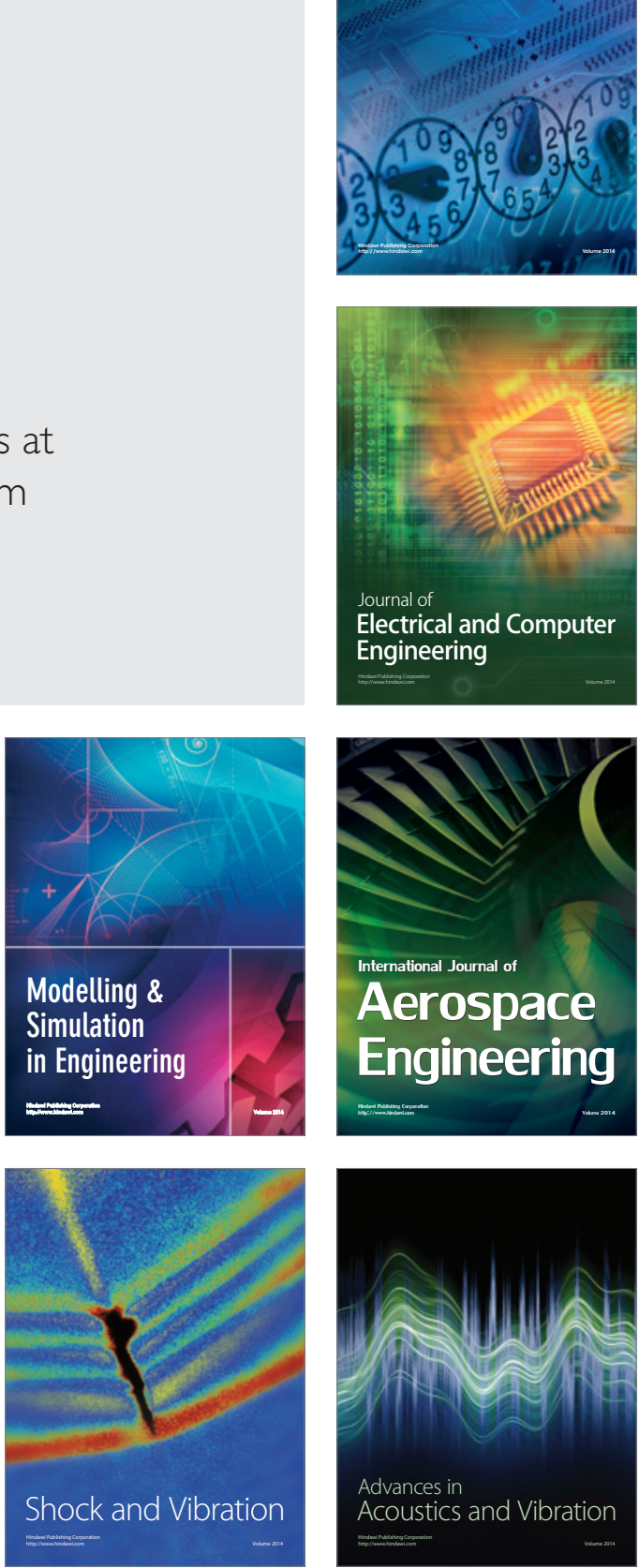